\title{
The counseling african americans to control hypertension (caatch) trial: baseline demographic, clinical, psychosocial, and behavioral characteristics
}

\author{
Senaida Fernandez ${ }^{1}$, Jonathan N Tobin ${ }^{2,3}$, Andrea Cassells ${ }^{2}$, Marleny Diaz-Gloster ${ }^{2}$, Chamanara Kalida ${ }^{2}$ and \\ Gbenga Ogedegbe 1* $^{*}$
}

\begin{abstract}
Background: Effectiveness of combined physician and patient-level interventions for blood pressure (BP) control in low-income, hypertensive African Americans with multiple co-morbid conditions remains largely untested in community-based primary care practices. Demographic, clinical, psychosocial, and behavioral characteristics of participants in the Counseling African American to Control Hypertension (CAATCH) Trial are described. CAATCH evaluates the effectiveness of a multi-level, multi-component, evidence-based intervention compared with usual care (UC) in improving BP control among poorly controlled hypertensive African Americans who receive primary care in Community Health Centers (CHCs).
\end{abstract}

Methods: Participants included 1,039 hypertensive African Americans receiving care in 30 CHCs in the New York Metropolitan area. Baseline data on participant demographic, clinical (e.g., BP, anti-hypertensive medications), psychosocial (e.g., depression, medication adherence, self-efficacy), and behavioral (e.g., exercise, diet) characteristics were gathered through direct observation, chart review, and interview.

Results: The sample was primarily female (71.6\%), middle-aged (mean age $=56.9 \pm 12.1$ years), high school educated (62.4\%), low-income (72.4\% reporting less than \$20,000/year income), and received Medicaid (35.9\%) or Medicare (12.6\%). Mean systolic and diastolic BP were $150.7 \pm 16.7 \mathrm{~mm} \mathrm{Hg}$ and $91.0 \pm 10.6 \mathrm{~mm} \mathrm{Hg}$, respectively. Participants were prescribed an average of $2.5 \pm 1.9$ antihypertensive medications; $54.8 \%$ were on a diuretic; $33.8 \%$ were on a beta blocker; $41.9 \%$ were on calcium channel blockers; $64.8 \%$ were on angiotensin converting enzyme (ACE) inhibitors/angiotensin receptor blockers (ARBs). One-quarter (25.6\%) of the sample had resistant hypertension; one-half (55.7\%) reported medication non-adherence. Most (79.7\%) reported one or more co-morbid medical conditions. The majority of the patients had a Charlson Co-morbidity score $\geq 2$. Diabetes mellitus was common (35.8\%), and moderate/severe depression was present in 16\% of participants. Participants were sedentary ( $835.3 \pm$ 1,644.2 Kcal burned per week), obese (59.7\%), and had poor global physical health, poor eating habits, high health literacy, and good overall mental health.

Conclusions: A majority of patients in the CAATCH trial exhibited adverse lifestyle behaviors, and had significant medical and psychosocial barriers to adequate BP control. Trial outcomes will shed light on the effectiveness of evidence-based interventions for BP control when implemented in real-world medical settings that serve high numbers of low-income hypertensive African-Americans with multiple co-morbidity and significant barriers to behavior change.

\footnotetext{
* Correspondence: olugbenga.ogedegbe@nyumc.org

${ }^{1}$ Center for Healthful Behavior Change, Division of General Internal Medicine, Department of Medicine, New York University School of Medicine, 550 First Avenue, New York, NY, USA

Full list of author information is available at the end of the article
} 


\section{Background}

Hypertension affects approximately 65 million adults in the United States [1], and disproportionately affects African Americans in terms of prevalence, treatment, and control rates compared to whites $[2,3]$. These disparities may explain the poorer adverse hypertensionrelated outcomes in African Americans [4]. The cardiovascular benefits of blood pressure (BP) control are well-documented [5], as are the utility of patient- and provider-centered interventions in promoting BP control [6-9]. Lifestyle interventions of reduced sodium intake $[7,10]$ and other dietary modifications (increased consumption of fiber, fruits, vegetables, and low fat dairy; reduced consumption of saturated and total fat) [11], and increased physical activity and weight loss [6] have resulted in significant BP reduction. While these interventions have proven efficacious in clinical trials, and although there are many community-based interventions that engage African Americans (and are often conducted in low-income communities), their effectiveness remains largely untested among hypertensive African Americans who receive care in low-resource settings such as Community Health Centers (CHCs).

The Counseling African Americans to Control Hypertension (CAATCH) trial [12] was designed to evaluate, in a cluster randomized trial, the effectiveness of a multi-level, multi-component, evidence-based intervention compared to usual care (UC) in improving BP control in hypertensive African Americans who receive care in CHCs. The trial targets barriers to optimal hypertension control at the patient, provider, and practice levels in a large cohort of African American adults $(\mathrm{n}=$ 1,039) [12]. As such, this trial has the potential to expand our understanding of barriers and facilitators of intervention implementation in 'real-world' clinical settings, as well as the effectiveness of lifestyle interventions in previously understudied and underserved populations. This paper describes the demographic, clinical, psychosocial, and behavioral characteristics of CAATCH trial participants in order to highlight some of the patient-related barriers to hypertension control present in this sample.

\section{Methods}

\section{Study Design and Setting}

A detailed description of the rationale, design, and methods of this trial has been published elsewhere [12]. The study protocol was approved by the Institutional Review Boards (IRBs) of Columbia University, New York University, and Clinical Directors Network (CDN), and all participants provided informed consent to participate. Briefly, CAATCH is a two-arm, cluster-randomized controlled trial (RCT) implemented in $30 \mathrm{CHCs}$, with 15 sites randomly assigned to the intervention condition (IC) and 15 to UC.

\section{Participants}

The participants included 1,039 African American adult men and women. Patients were eligible for the study if they: self-identified as black or African American; were at least 18 years old, were receiving care at the participating $\mathrm{CHC}$ for at least six months prior to enrollment; had a diagnosis of hypertension (HTN), were taking at least one anti-hypertensive medication, and had uncontrolled BP at the time of enrollment based on standardized measurement at study visit (systolic BP (SBP) $\geq$ $140 \mathrm{~mm} \mathrm{Hg}$ or diastolic BP (DBP) $\geq 90 \mathrm{mmHg}$; for those with diabetes or kidney disease, SBP $\geq 130 \mathrm{~mm}$ $\mathrm{Hg}$ or DBP $\geq 80 \mathrm{~mm} \mathrm{Hg}$ ). Additional details on inclusion and exclusion criteria have been published elsewhere [12]. Figure 1 shows the flow of patients through the study in a CONSORT [13] diagram.

\section{Interventions}

The intervention was implemented at the practice level, such that all physicians and patients at a given site were in the same treatment condition: IC or UC. Within the IC sites, the CAATCH intervention is comprised of three components targeted at patients (interactive computerized hypertension education, home BP monitoring, and monthly behavioral counseling on lifestyle modification) and two components targeted at physicians (monthly CME-accredited case rounds based on JNC-7 guidelines [5], chart audit and provision of feedback on clinical performance, and patients' home BP readings). Additional details on the intervention and its delivery are described elsewhere [12].

\section{Objectives}

The goal of CAATCH was to evaluate, in cluster randomized trial, the effectiveness of a multi-level, multi-component, evidence-based intervention compared to UC in improving BP control among hypertensive African Americans who receive care in $\mathrm{CHCs}$. We hypothesize that patients randomized to the IC will have, compared to those in the UC condition: a higher $\mathrm{BP}$ control rate at 12 months; greater reduction in both SBP and DBP at 12 months; and a higher rate of maintenance of intervention effect one year after completion of the trial. In addition, the IC will be more cost-effective in improving $\mathrm{BP}$ control rate at 12 months compared to UC.

\section{Outcomes}

The primary outcome was the proportion of patients with adequate $\mathrm{BP}$ control at 12 months; and the maintenance of intervention effects one year after the trial. BP was defined as uncontrolled if the average $\mathrm{BP} \geq 140 \mathrm{~mm}$ 


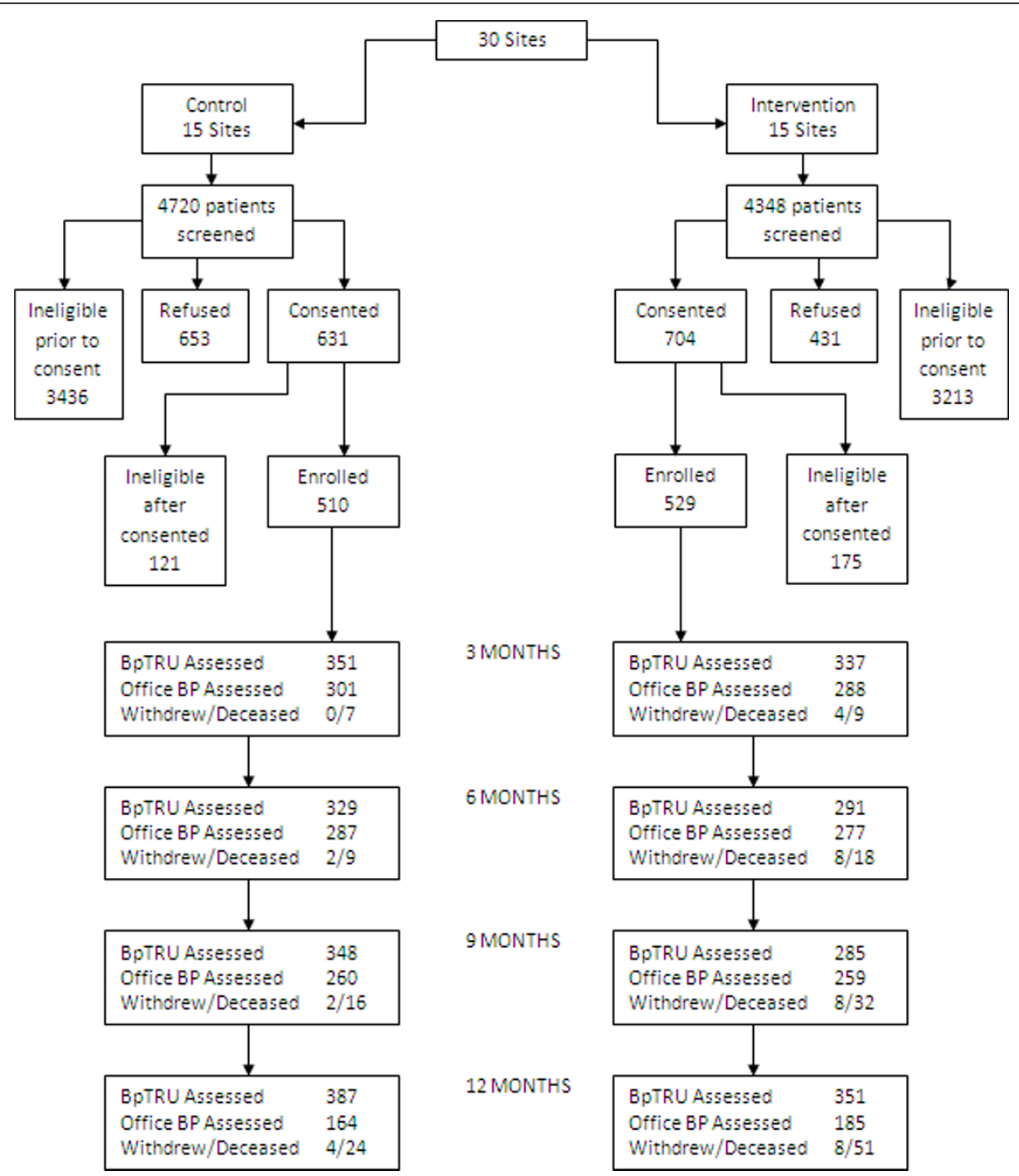

Figure 1 Flow of participants through study

$\mathrm{Hg}$ or DBP $\geq 90 \mathrm{~mm} \mathrm{Hg}$ (for those without comorbidity) OR average $\mathrm{SBP} \geq 130 \mathrm{~mm} \mathrm{Hg}$ or DBP $\geq 80 \mathrm{~mm}$ $\mathrm{Hg}$ (for those with diabetes or kidney disease). The secondary outcomes are within-patient change in BP from baseline to 12 months, and the cost effectiveness of intervention at 12 months.

\section{Data collection}

Data collection and study measurements were performed by trained research assistants (RAs) via interviews, direct measurements, and chart review. A complete listing of all measures and details of assessment protocol has been published elsewhere [12]. At baseline, three BP readings were taken by trained RAs using a validated automated BP monitor (BPTru, Model BPM-300; BpTRU Medical Devices, Coquitlam, BC, Canada) with the patient seated comfortably and following American Heart Association (AHA) guidelines [14]. The average of the three readings was used as the measure for baseline assessment. Psychosocial and behavioral characteristics were assessed with validated selfreport measures and included medication adherence (4item Morisky Scale) [15], self-efficacy (Medication Adherence Self-Efficacy Scale; MASES) [16], health literacy (Rapid Estimate of Adult Literacy in Medicine; REALM) [17], dietary intake (Rapid Eating Assessment for Patients; REAP) [18], physical activity (Paffenbarger Physical Activity Scale) [19], daytime sleepiness (Epworth Sleepiness Scale) [20], depression (Patient Health Questionnaire-9; PHQ-9) [21], and general physical and mental health (version one of the 12-Item Short Form Health Survey; SF-12) [22]. At the CHC site level, data were gathered on whether $\mathrm{CHCs}$ utilized electronic health records (EHRs), and whether they were part of 
the Health Resources and Services Administration (HRSA) Health Disparities Collaboratives http://www. healthcarecommunities.org. The HRSA sponsored Health Disparities Collaboratives (HDCs) use the structure of the Chronic Care Model (CCM), which is an organizational approach to caring for people with chronic disease who are seen in a primary care setting. The system is population-based, and creates practical, supportive, evidence-based interactions between an informed, activated patient and a prepared, proactive practice team; it identifies six major categories that must be addressed to achieve substantial change, including the healthcare organization, community resources and policies, self-management support, decision support, delivery system design, and clinical information systems [23].

\section{Power analysis and sample size}

The design for the CAATCH trial was based on power calculations for the proposed analysis of differential changes in office SBP and DBP between IC and UC sites (CHCs). These calculations were based on postintervention data available from Phase one of the medication Adherence and Blood Pressure Control (ABC) trial, which was conducted by this research group in several of the same CHCs [24]. BPs for those in the $\mathrm{ABC}$ trial home blood pressure monitoring (HBPM) intervention $(n=137)$ were compared to those in the $\mathrm{UC}$ group $(\mathrm{n}=80)$ in nine sites, and office BPs decreased substantially in both conditions (SBP/DBP decreased 12.0/6.0 $\mathrm{mmHg}$ in HBPM versus $8.7 / 3.8$ $\mathrm{mmHg}$ in UC). Of note, they decreased more $(3.3 / 2.2$ $\mathrm{mmHg}, p=0.053 / 0.078)$ in the HBPM condition. Clustered sampling due to patients being nested within sites was controlled for, yielding estimates of the between-site and within-site variances in treatment effect (5.13 and 154.21 for SBP, and 1.72 and 86.35 for DBP). Sites were the primary unit of analysis, given that sites are randomized to treatment condition. To estimate the number of sites required, the within-treatment, between-site variance of site-level mean change scores was first estimated. This is estimated as the between-site (true) variance plus the sampling variability of the site mean. For SBP, this was $5.13 \pm 154.21 /$ Nsite, and for DBP it was $1.72 \pm 86.35 /$ Nsite, where Nsite is the number of patients per site. We initially planned for 30 patients per site, yielding variance estimates of 10.28 and 4.60 for site-level mean changes in SBP and DBP; taking square roots gives standard deviation estimates of 3.21 and 2.14. These estimates and the usual power calculations for a t-test were used to determine the number of sites needed to have adequate power to detect a specified effect size. With a total of 30 sites (with 30 patients at each site), 15 assigned to each condition (IC and UC), these estimates implied that there would be $80 \%$ and $81 \%$ power to detect SBP and DBP treatment effects equal to the HBPM effect reported above (using a 2tailed, 0.05-level test). Because of the multifaceted nature of the intervention that was implemented in this study, it is reasonable to anticipate treatment effects of at least $4 \mathrm{~mm} \mathrm{Hg}$ for SBP and $3 \mathrm{~mm} \mathrm{Hg}$ for DBP. The estimated power to detect effects of this magnitude is $91 \%$ and $96 \%$, respectively. Thus, based on this power analysis, we planned to randomize 30 sites (1:1). Because we anticipated approximately a $15 \%$ rate of attrition, the enrollment target was set at 1,058 patients from these sites, which would yield a final sample of 900 patients who complete the study (an average of 30 per site).

\section{Analytic plan}

The CAATCH trial has three nested levels of sampling: site, physician, and patient. Sites were matched for size (large/medium versus small), creating 15 matched pairs. Within each pair, one site was randomly assigned to IC and the other to UC. Due to a variety of unspecified factors, it was assumed that patients from the same site, and perhaps also patients having the same physician, would be somewhat more similar than randomly selected patients attending different $\mathrm{CHCs}$ or having different physicians. This implies correlated residuals due to 'clustered sampling,' that will be controlled in the primary outcome analysis by treating both $\mathrm{CHC}$ and clinician within $\mathrm{CHC}$ as random factors. Maximum likelihood estimates, approximate standard errors, and multi-level modeling statistical tests for primary outcome analysis will be obtained using PROC MIXED (SAS) [25,26]. The comparison of treatment groups with respect to dichotomous or ordinal measures (e.g., gender or smoker) will be performed using the MIXOR software $[27,28]$, which estimates a logistic regression (with random effects). The clustered sampling effects associated with $\mathrm{CHC}$ and physician will be adjusted for in the equation. As appropriate, the model will be further augmented to include both person-level covariates (e.g., gender) and time-varying covariates (e.g., body mass index). As stated, the primary hypothesis concerns the treatment by time interaction.

\section{Results \\ CHC characteristics}

The $30 \mathrm{CHCs}$ serve primarily low-income, African American populations. The median household yearly income in $\mathrm{CHC}$ zip codes was $\$ 32,499(\mathrm{SD}=\$ 17,054)$ and mean percentage of African American adults in $\mathrm{CHC}$ zip codes was $53 \%$ ( $\mathrm{SD}=27 \%$ ). A majority of the sites in the trial were located in metropolitan New York City (NYC) (73.30\%), upstate New York (13.30\%), and northern New Jersey (13.30\%). The IC and UC sites 
were similar in characteristics (all $p$-values $\geq 0.05$ ). The mean number of patients seen at the CHCs was 10,432 patients $(\mathrm{SD}=13,157)$ with $33.33 \%$ of sites classified as 'large' or 'extra large' CHC. Only a quarter of sites utilized EHRs, and less than one-half were participating in the HRSA Health Disparities Collaborative (see Table 1).

\section{Clinician characteristics}

CAATCH clinicians $(\mathrm{n}=94)$ were middle-aged $(M=$ $47.0 \pm 14.1$ years); $57 \%$ female; $43 \%$ African American, 24\% White, 9\% Hispanic; 57\% were U.S. Born; had MD/ DO degree (75\%); had worked in their $\mathrm{CHC}$ an average of $8.0 \pm 6.5$ years. There were an average of 4.4 clinicians per $\mathrm{CHC}$.

\section{Demographic characteristics}

CAATCH participants were middle-aged $(M=56.9 \pm$ 12.1 years), primarily female (71.6\%), high-school educated (62.4\%) and U.S. born (74.6\%). Participants who were foreign-born had lived in the U.S. an average of $20 \pm 12.4$ years. One-half $(54.0 \%)$ were insured through Medicaid and Medicare. As compared to UC, IC participants were more likely to be low-income (IC $=78.6 \%$ versus $\mathrm{UC}=65.8 \%, p<0.01)$ and have no health insurance $(\mathrm{IC}=11.3 \%$ versus $\mathrm{UC}=3.4 \%, p$ $<0.01$; see Table 2).

\section{Clinical characteristics}

Baseline mean SBP and DBP were $150.7 \pm 16.7 \mathrm{~mm} \mathrm{Hg}$ and $91.0 \pm 10.6 \mathrm{~mm} \mathrm{Hg}$, respectively. SBP was significantly higher in the UC group $(152.1 \pm 16.8)$ compared to the IC group $(149.3 \pm 16.5, p=0.007)$. There were no between group differences for DBP. Resistant hypertension, defined as any patient taking at least three antihypertensive medications including a diuretic, was present among $25.6 \%$ of participants. Over one-half of the participants were obese, and an additional one-quarter was overweight. Most (79.7\%) reported one or more co-morbid conditions, with over one-half (55.1\%) reporting two or more, and a sample mean Charlson Comorbidity score of $2.5 \pm 2.5$. Diabetes mellitus was the most commonly reported co-morbid condition (35.8\%), and congestive heart failure ( $\mathrm{CHF}$ ) was more common among UC (13.5\%) than IC (7.5\%) participants $(p=0.002$; See Table 3$)$.

$\mathrm{CAATCH}$ participants were taking an average of 2.5 antihypertensive medications, with over one-third of the sample taking three or more medications. Over one-half of the participants were on a diuretic (alone or in combination with other drugs); the most common antihypertensive medication prescribed for patients in this study was ACE/ARBs with over two-thirds of the patients, and a little over one-half were prescribed diuretic alone on in combination with other drugs (see Table 4).

\section{Psychosocial and behavioral characteristics}

One-half of CAATCH participants reported medication non-adherence to their antihypertensive medication $(55.7 \%)$, with a larger proportion of non-adherence in the UC group (63.1\%) compared to the IC group (48.7\%, $p<0.01)$. Self-efficacy for medication taking was lower in the UC group $(M=2.2 \pm 0.6)$ than the IC group $(M=$ $2.3 \pm 0.6, p=0.02)$. With regards to health literacy, a smaller proportion of UC participants (54.1\%), compared to IC participants $(60.8 \%)$ demonstrated high health literacy (61 to 66 points range) on the REALM, $(p=0.04)$. Differences in eating behaviors were also found between groups, with IC participants engaging in slightly less healthy eating $(M=1.7 \pm 0.8)$ compared to UC participants $(M=1.9 \pm 0.8, p=0.006)$.

Assessments of depression (PHQ-9), physical activity (Paffenbarger Physical Activity Scale) and general mental and physical functioning (SF-12) suggest that while mental health scores were generally within normal limits, on average, participants experienced some limitations in their physical functioning. The mean score on the Mental Component Summary (MCS) of the SF-12

Table 1 Community Health Center (CHC) Characteristics at Baseline

\begin{tabular}{|c|c|c|c|c|}
\hline Characteristic & $\begin{array}{l}\text { Total } \\
(\mathrm{n}=30)\end{array}$ & $\begin{array}{l}\text { Intervention Group } \\
(\mathrm{n}=15)\end{array}$ & $\begin{array}{l}\text { Usual Care Group } \\
(n=15)\end{array}$ & $p$ \\
\hline$\overline{N Y C}$ & 73.3 & 66.7 & 80.00 & 0.08 \\
\hline Upstate NY & 13.3 & 6.7 & 20.00 & \\
\hline NJ & 13.3 & 26.7 & 0.00 & \\
\hline Size/\#Users (SD) & $10,432(13,157)$ & $9,311(8,234)$ & $11,553(16,973)$ & 0.65 \\
\hline$\%$ Large $\mathrm{CHC}$ & 33.3 & 33.3 & 33.3 & 1.0 \\
\hline \% Using Electronic Health Records (EHR) & 26.7 & 20.0 & 33.3 & 0.41 \\
\hline \% Participating in HRSA Health Disparities Collaboratives (HDC) & 43.3 & 46.7 & 40.0 & 0.71 \\
\hline Median Household Income in Zip Code & $32,499(17,054)$ & $28,352(11,196)$ & $36,645(20,982)$ & 0.19 \\
\hline Mean\% African American Adults in Zip (SD) & $52.6(27.2)$ & $57.1(27.5)$ & $48.3(27.2)$ & 0.38 \\
\hline
\end{tabular}

Note. \# Users = total number of patients across all divisions of care. HRSA = Health Resources and Services Administration. 
Table 2 Demographic Characteristics of Participants at Baseline

\begin{tabular}{|c|c|c|c|c|}
\hline Characteristic & $\begin{array}{l}\text { Total } \\
(n=1,039)\end{array}$ & $\begin{array}{l}\text { Intervention Group } \\
(\mathrm{n}=529)\end{array}$ & $\begin{array}{l}\text { Usual Care } \\
\text { Group } \\
(n=510)\end{array}$ & $p$ \\
\hline Age in Years (mean $\pm s d ; n=1,026)$ & $56.9 \pm 12.1$ & $56.7 \pm 11.5$ & $57.0 \pm 12.8$ & 0.72 \\
\hline Age $\geq 65$ Years $(\% ; n=1,026)$ & 26.5 & 26.8 & 26.2 & 0.85 \\
\hline \multicolumn{5}{|l|}{ Gender $(\% ; n=1,014)$} \\
\hline Female & 71.6 & 69.3 & 74.0 & 0.10 \\
\hline \multicolumn{5}{|l|}{ Ethnicity $(\% ; n=953)$} \\
\hline Non-Hispanic & 93.3 & 94.3 & 92.2 & 0.21 \\
\hline Hispanic & 6.7 & 5.7 & 7.8 & \\
\hline \multicolumn{5}{|l|}{ Place of Birth $(\% ; n=941)$} \\
\hline USA & 74.60 & 76.4 & 72.6 & 0.18 \\
\hline Non-USA & 25.40 & 23.6 & 27.4 & \\
\hline \multicolumn{5}{|l|}{ Marital Status $(\% ; n=953)$} \\
\hline Separated/Divorced/Widowed & 44.7 & 48.0 & 41.3 & 0.07 \\
\hline Married & 25.8 & 25.5 & 26.1 & \\
\hline Never married & 29.5 & 26.5 & 32.6 & \\
\hline \multicolumn{5}{|l|}{ Education Level (\%; n = 956) } \\
\hline$\geq$ High School & 62.4 & 59.9 & 65.2 & 0.14 \\
\hline$<$ High School & 36.9 & 39.7 & 34.0 & \\
\hline None & 0.6 & 0.4 & 0.9 & \\
\hline \multicolumn{5}{|l|}{ Employment Status $(\% ; n=944)$} \\
\hline Not employed & 11.0 & 12.3 & 9.6 & 0.15 \\
\hline Retired or Homemaker & 55.2 & 57.1 & 53.2 & \\
\hline Employed: Part-time & 13.6 & 12.1 & 15.1 & \\
\hline Employed: Full-time & 20.2 & 18.5 & 22.1 & \\
\hline \multicolumn{5}{|l|}{ Income $(\% ; n=940)$} \\
\hline$<\$ 20,000 /$ year & 72.4 & 78.6 & 65.8 & $<0.01^{* *}$ \\
\hline$\geq \$ 20,000 /$ year & 27.6 & 21.4 & 34.2 & \\
\hline \multicolumn{5}{|l|}{ Insurance Status (\%; n = 917) } \\
\hline Medicaid & 35.9 & 38.7 & 32.9 & $<0.01^{* *}$ \\
\hline Medicare & 12.6 & 12.6 & 12.8 & \\
\hline Medicaid and Medicare & 5.5 & 6.4 & 4.5 & \\
\hline Private/HMO & 19.0 & 13.8 & 24.4 & \\
\hline None & 7.4 & 11.3 & 3.4 & \\
\hline Other\# & 19.6 & 17.2 & 22.1 & \\
\hline
\end{tabular}

Note. Data gathered through interview. \#Category includes VA insurance; combination/multiple sources of coverage. ${ }^{*} p<0.05 ;{ }^{* *} p<0.01$

was $48.0 \pm 11.2$. When comparing SF-12 MCS mean scores between groups, the UC group scored significantly lower $(M=47.1 \pm 11.6)$ in overall mental health than the IC group $(M=48.7 \pm 10.8, p=0.03)$. Mean scores on PHQ-9 depression measure indicated that the UC group $(M=5.4 \pm 4.7)$ scored in the mildly depressed range (PHQ-9 score $\geq 5$ ) [21] and significantly higher than the IC group $(M=4.5 \pm 4.6, p=$ 0.005). Approximately sixteen percent of the participants reached the cut-off for moderate/severe major depressive disorder (PHQ-9 score $\geq 10$ ) [21]. The Physical Component Summary (PCS) score of the SF-12 was $42.3 \pm 10.4$, and the UC group scored significantly lower $(M=41.6 \pm 10.9)$ on the scale than the IC group $(M=$ $43.0 \pm 9.8, p=0.04)$. Paffenbarger Physical Activity
Scale mean scores indicated that $\mathrm{CAATCH}$ participants were sedentary, burning on average $835.3 \pm 1,644.2 \mathrm{Kcal}$ per week in physical activity. While sleep quality scores $(M=7.0 \pm 4.7)$ fell within the Epworth Sleepiness Scale (ESS) normal range (0 to 9) [20,29], one-fifth (20.9\%) experienced problematic levels of daytime sleepiness, as indicated by scores of 10 or greater on the scale (see Table 5).

\section{Discussion}

In this paper we describe the baseline characteristics of African American patients enrolled in the CAATCH trial, a cluster RCT multi-level, practice-based, BP control trial among a sample of $\mathrm{CHCs}$ with a rich diversity of demographic, clinical, psychosocial, and behavioral 
Table 3 Clinical Characteristics of Participants at Baseline

\begin{tabular}{|c|c|c|c|c|}
\hline Characteristic & $\begin{array}{l}\text { Total } \\
(n=1,039)\end{array}$ & $\begin{array}{l}\text { Intervention Group } \\
(n=529)\end{array}$ & $\begin{array}{l}\text { Usual Care Group } \\
(\mathrm{n}=510)\end{array}$ & $p$ \\
\hline \multicolumn{5}{|l|}{ Baseline $\mathrm{BP} \wedge$ (mean $\pm \mathrm{sd} ; \mathrm{n}=1,039$ ) } \\
\hline SBP & $150.7 \pm 16.7$ & $149.3 \pm 16.5$ & $152.1 \pm 16.8$ & $<0.01^{* *}$ \\
\hline DBP & $91.0 \pm 10.6$ & $90.8 \pm 10.7$ & $91.2 \pm 10.5$ & 0.54 \\
\hline Resistant Hypertensiont (\%; n = 912) & 25.6 & 27.8 & 23.6 & 0.15 \\
\hline \multicolumn{5}{|l|}{ Smoking Statust (\%; $n=939$ ) } \\
\hline Current & 29.8 & 32.0 & 27.5 & 0.08 \\
\hline Former & 20.9 & 22.3 & 19.4 & \\
\hline Never & 49.3 & 45.8 & 53.1 & \\
\hline \multicolumn{5}{|l|}{ Body Mass Indext (\%; n = 647) } \\
\hline Mean (SD), kg/m² & $32.5(7.9)$ & $32.6(7.6)$ & $32.4(8.4)$ & 0.77 \\
\hline Overweight & 26.3 & 28.3 & 23.2 & 0.15 \\
\hline Obese & 59.7 & 59.9 & 59.3 & \\
\hline \multicolumn{5}{|c|}{ Number of Co-morbid Conditionsł $(\% ; n=929)$} \\
\hline 0 & 20.3 & 18.3 & 22.3 & $0.03^{*}$ \\
\hline 1 & 24.6 & 28.1 & 20.9 & \\
\hline 2 to 3 & 35.6 & 36.2 & 35.0 & \\
\hline$>3$ & 19.5 & 17.3 & 21.8 & \\
\hline \multicolumn{5}{|l|}{ Comorbid Conditions $\neq(\% ; n=964)$} \\
\hline Charlson Score (mean \pm sd; $n=965)$ & $2.5 \pm 2.5$ & $2.4 \pm 2.5$ & $2.5 \pm 2.5$ & 0.70 \\
\hline Chronic Kidney Disease & 2.5 & 2.4 & 2.6 & 0.87 \\
\hline Myocardial Infarction & 7.4 & 6.9 & 7.9 & 0.53 \\
\hline Congestive Heart Failure & 10.4 & 7.5 & 13.5 & $<0.01^{* *}$ \\
\hline Stroke & 10.9 & 9.9 & 12.0 & 0.30 \\
\hline Diabetes Mellitus & 35.8 & 37.2 & 34.3 & 0.35 \\
\hline
\end{tabular}

Note. Data gathered through: $\wedge$ direct observation, tchart review, finterview. BP = Blood Pressure; HTN $=$ Hypertension. ${ }^{*} p<0.05 ;{ }^{* *} p<0.01$

characteristics. Results from this trial will provide valuable information on interventions to promote BP control in a high-risk population of hypertensive African Americans with uncontrolled BP.

There were a number of patient-level barriers to hypertension control among the CAATCH sample at baseline, including low-income, significant co-morbidity, sedentary lifestyle, smoking, overweight, and obesity. This sample had a considerably lower mean income compared to patients in large-scale epidemiological studies, such as the multi-ethnic Dallas Heart Study [30,31] and the Jackson Heart Study $[32,33]$. When compared to other large-scale trials in hypertensive African Americans, CAATCH participants were more likely to be in

Table 4 Blood Pressure Medications at Baseline

\begin{tabular}{|c|c|c|c|c|}
\hline & $\begin{array}{l}\text { Total } \\
(n=1,039)\end{array}$ & $\begin{array}{l}\text { Intervention Group } \\
(\mathrm{n}=529)\end{array}$ & $\begin{array}{l}\text { Usual Care } \\
\text { Group } \\
(\mathrm{n}=510)\end{array}$ & $p$ \\
\hline \multicolumn{5}{|l|}{ Number of Drugs in Hypertension Regimen $(\% ; n=907)$} \\
\hline 1 & 32.7 & 30.1 & 35.8 & \\
\hline 2 & 30.1 & 29.1 & 31.3 & \\
\hline 3 & 18.0 & 20.4 & 15.1 & \\
\hline$\geq 4$ & 19.2 & 20.4 & 17.8 & 0.08 \\
\hline On a Diuretic $(\% ; n=912)$ & 54.8 & 54.6 & 55.1 & 0.86 \\
\hline On a Beta Blocker (\%; $\mathrm{n}=912)$ & 33.8 & 30.4 & 37.7 & $0.02^{*}$ \\
\hline If on a 2-Drug Regimen (\%; $n=273)$, Percent on a Diuretic & 57.9 & 57.3 & 58.5 & 0.85 \\
\hline If on a 3-Drug Regimen (\%; $n=163)$, Percent on a Diuretic & 63.2 & 65.0 & 60.3 & 0.55 \\
\hline If on a 3-Drug or Greater Regimen $(n=337)$, Percent on a Diuretic & 70.0 & 68.5 & 72.3 & 0.46 \\
\hline If on a 2-drug Regimen $(n=273)$, Percent on ACE $+C C B$ & 6.2 & 6.3 & 6.2 & 0.96 \\
\hline
\end{tabular}

Note. Data gathered through chart review. 
Table 5 Psychosocial and Behavioral Characteristics of Participants at Baseline

\begin{tabular}{|c|c|c|c|c|}
\hline Characteristic & $\begin{array}{l}\text { Total } \\
(n=1,039)\end{array}$ & $\begin{array}{l}\text { Intervention Group } \\
(\mathrm{n}=529)\end{array}$ & $\begin{array}{l}\text { Usual Care } \\
\text { Group } \\
(n=510)\end{array}$ & $p$ \\
\hline Medication Non-adherence $(\% ; n=961)$ & 55.7 & 48.7 & 63.1 & $<0.01^{* *}$ \\
\hline Medication Adherence Self-Efficacy Scale (MASES; mean \pm sd; $n=787$ ) & $2.2 \pm 0.6$ & $2.3 \pm 0.6$ & $2.2 \pm 0.6$ & $0.02^{*}$ \\
\hline Rapid Estimate of Adult Literacy in Medicine (REALM; mean \pm sd; \%; $n=889$ ) & $56.9 \pm 13.2$ & $57.3 \pm 12.8$ & $56.4 \pm 13.6$ & 0.28 \\
\hline $3^{\text {rd }}$ Grade $(0$ to 18$)$ & 3.5 & 3.0 & 4.0 & $0.04^{*}$ \\
\hline $4^{\text {th }}$ to $6^{\text {th }}$ Grade (19 to 44$)$ & 8.8 & 9.9 & 7.5 & \\
\hline $7^{\text {th }}$ to $8^{\text {th }}$ Grade ( 45 to 60 ) & 30.1 & 26.3 & 34.4 & \\
\hline $9^{\text {th }}$ Grade and Greater (61 to 66 ) & 57.6 & 60.8 & 54.1 & \\
\hline $\begin{array}{l}\text { Rapid Eating Assessment for Patients } \\
\text { (REAP; mean } \pm s d ; n=930 \text { ) }\end{array}$ & $1.8 \pm 0.8$ & $1.7 \pm 0.8$ & $1.9 \pm 0.8$ & $<0.01^{* *}$ \\
\hline \multirow[t]{2}{*}{ Paffenbarger Physical Activity Scale (mean \pm sd; \%; $n=951$ ) } & $835.3 \mathrm{Kcal} \pm$ & $833 \mathrm{Kcal} \pm$ & $837.8 \mathrm{Kcal} \pm$ & 0.97 \\
\hline & 1,644.2 Kcal & $1,856.8 \mathrm{Kcal}$ & $1,388.9 \mathrm{Kcal}$ & 0.87 \\
\hline Sedentary $(<500 \mathrm{Kcal} /$ week $)$ & 54.1 & 54.3 & 53.8 & \\
\hline Insufficiently Active (500 to $999 \mathrm{Kcal} /$ week) & 25.1 & 24.4 & 25.8 & \\
\hline Regularly Active ( $\geq 1,000 \mathrm{Kcal} /$ week) & 20.8 & 21.3 & 20.4 & \\
\hline Epworth Sleepiness Scale (mean \pm sd; \%; $n=949$ ) & $7.0 \pm 4.7$ & $6.9 \pm 4.8$ & $7.2 \pm 4.6$ & 0.46 \\
\hline Normal $(\geq 10)$ & 79.1 & 80.2 & 78.0 & 0.40 \\
\hline Excessive Daytime Sleepiness (> 10) & 20.9 & 19.8 & 22.0 & \\
\hline Patient Health Questionnaire-9 $($ mean \pm sd; $\% ; n=850)$ & $4.9 \pm 4.7$ & $4.5 \pm 4.6$ & $5.4 \pm 4.7$ & $<0.01^{* *}$ \\
\hline Minimal (0 to 4) & 56.2 & 59.4 & 52.8 & 0.28 \\
\hline Mild (5 to 9 ) & 28.1 & 26.3 & 30.1 & \\
\hline Moderate (10 to 14$)$ & 10.9 & 10.4 & 11.5 & \\
\hline Moderately Severe (15 to 19) & 4.1 & 3.2 & 5.1 & \\
\hline Severe (20 to 27 ) & 0.6 & 0.7 & 0.5 & \\
\hline \multicolumn{5}{|l|}{ SF-12 (mean \pm sd; $n=939)$} \\
\hline PCS-12 & $42.3 \pm 10.4$ & $43.0 \pm 9.8$ & $41.6 \pm 10.9$ & $0.04^{*}$ \\
\hline MCS-12 & $48.0 \pm 11.2$ & $48.7 \pm 10.8$ & $47.1 \pm 11.6$ & $0.03^{*}$ \\
\hline
\end{tabular}

Note. Data gathered through interview. PCS-12 = Physical Component Summary; MCS-12 = Mental Component Summary. ${ }^{*} p<.05 ;{ }^{*} p<0.01$

particularly poor health. For example, CAATCH participants were heavier than those in the Dallas Heart Study [30], Jackson Heart Study [33], in Dietary Approaches to Stop Hypertension (DASH), Hypertension Improvement Project (HIP), and PREMIER trials [6,11,34]. Obesity rates reported for African Americans in the National Health and Nutrition Examination Survey (NHANES) were only $45 \%[35,36]$, compared to over two-thirds reported in CAATCH. Similar to published data on medication adherence [15,37-39], one-half of the $\mathrm{CAATCH}$ participants reported non-adherence, and they experienced diabetes and cardiovascular disease at rates higher than samples in large scale epidemiological trials such as the Jackson Heart Study [33]. In fact, CAATCH participants reported higher co-morbid medical conditions, which are recognized as significant barriers to BP control [40]. Physical activity levels in the CAATCH sample were very low, with most of the participants characterized as sedentary or insufficiently active. This a higher proportion than rates noted in the most recent NHANES data [41]. A noteworthy finding is that prevalence of smoking in the CAATCH trial was higher than those in the Jackson Heart Study [33], the Dallas Heart Study [30], and recent NHANES data on smoking among overweight and obese adults [41]. Further attention is warranted for several of the CAATCH sample's psychosocial and behavioral characteristics. CAATCH participants reported a moderate level of self-confidence in their ability to take antihypertensive medications (as measured by the MASES) [16], and a low level of healthy eating (as measured by the REAP) [18]. While the average general mental health score (Mental Component Summary of the SF-12) [22] of participants fell within normal range of population based norms, the UC participants scored in the mildly depressed range (as assessed by the PHQ-921). Furthermore, participants reported limitations in general physical functioning (Physical Component Summary of the SF-12) [22]. Though, on average, participants scored within the normal range on an index of sleep quality $[20,29]$, problematic levels of daytime sleepiness (Epworth Sleep Scale score $\geq 10$ ) were present among one-fifth. This rate is higher than the prevalence of daytime somnolence observed in recent NHANES data [42], 
yet lower than rates found in a recent analysis from the Sleep Heart Health Study [43]. The problematic daytime sleepiness observed in $\mathrm{CAATCH}$ participants may be due in part to the higher prevalence of obesity, which is a major risk factor for obstructive sleep apnea $[44,45]$. One-quarter of CAATCH participants had resistant hypertension (defined as any patient with uncontrolled $\mathrm{BP}$ who is taking at least three antihypertensive medications, including a diuretic). While thiazide type diuretics are the recommended initial pharmacological treatment $[5,46]$, only one-half of the CAATCH sample had been prescribed one. However, this percentage is higher than the diuretic rate reported for a population of hypertensive patients from a large managed care organization, located in the southeastern United States, based on prescription fill data two years following publication of the JNC-7 guidelines [46].

One of the most striking aspects of the CAATCH trial is how its participants compare demographically and clinically to large-scale efficacy trials of lifestyle modification on BP levels $[6,7,11,47]$, and four recently published effectiveness trials of BP control [34,48-51]. Participation of African Americans in previous efficacy trials ranged from 25 to $50 \%$ of the sample $[6,7,11,34,49,51]$, while the CAATCH trial sample consists entirely of African American participants. Of particular note, the CAATCH trial represents a substantive improvement in African American male participation over previous trials in that almost one-third of participants were African American men. By contrast, one-tenth of participants in PREMIER were African American men. To our knowledge, the CAATCH trial includes the largest proportion of African American men in community practice-based trials. Because trust is a major hindrance to recruitment of minorities into clinical research [52], we adopted a two-pronged strategy to increase the participation of African American men, in addition to the traditional compensation provided to patients. First, we solicited the support of the $\mathrm{CHC}$ patient care coordinators and clerical staff in referring patients into the study. $\mathrm{CHC}$ staff typically interacts with patients over a longer period of time and have built significant rapport and trust with the patients, whereas research staff have a shorter duration and more circumscribed relationship with prospective study participations. Second, we asked the clinicians to refer their patients into the trial. This strategy also addresses the issue of trust, building on the existing relationships between patients and providers. In addition, we oversampled African American men, because women comprise $70 \%$ of the adult users of CHCs. Finally, we held series of educational sessions at the study sites to inform patients about the study and to identify and screen potentially eligible patients; refreshments were offered at these sessions.
To our knowledge, CAATCH is the largest practicebased trial of patient and physician targeted interventions for BP control in hypertensive African Americans. We are only aware of three other trials that have targeted both patients and physicians in practice-based settings $[34,49,50]$. The first is the HIP trial [34], which is a nested, $2 \times 2$ RCT comparing physician intervention, patient intervention, and both combined versus control condition, among 574 hypertensive patients in eight primary care practices (32 physicians) in central North Carolina. The second is the Veterans Study to Improve the Control of Hypertension (V-STITCH) trial [49], which is a 2-level (primary care provider and patient) cluster RCT among 588 hypertensive patients in a Veterans Affairs Medical Center primary care clinic (17 physicians) in North Carolina. The third is a study by Roumie et al., which is a cluster RCT [50] that evaluated the impact of three quality improvement interventions (provider education, provider education and alert, patient education) of increasing intensity among 1,341 hypertensive patients who received care in two hospitalbased and eight community-based outpatient clinics (182 providers) in the Veterans Affairs Tennessee Valley Healthcare System. One qualitative difference between $\mathrm{CAATCH}$ and these trials is that $\mathrm{CAATCH}$ was focused exclusively on African Americans. Second, the patients in $\mathrm{CAATCH}$ all had uncontrolled hypertension and greater co-morbidity than those in the other practicebased trials. Specifically, CAATCH participants had higher baseline BP, were more sedentary, had greater levels of co-morbidity, and higher current smoking rates than participants in the V-STITCH and HIP trials $[34,49]$. Furthermore, CAATCH participants had comparable rates of smoking and higher rates of diabetes, and lower rates of medication adherence than participants in Roumie et al. VA-based trial of interventions targeting providers and patients [50]. Perhaps of even more interest, participants in the $\mathrm{CAATCH}$ trial had lower income than those in the HIP, V-STITCH, DASH, and PREMIER trials, had less education than participants in DASH, and PREMIER, and as a group, were more likely to be underinsured. Thus, the patient population in $\mathrm{CAATCH}$ is more representative of lowincome African Americans with poorly controlled hypertension and numerous adverse lifestyle behaviors and clinical characteristics that constitute barriers to adequate BP control. As such, the findings from CAATCH will provide needed information on effectiveness of lifestyle and self-management approaches in care of this high-risk population in a more generalizable context. Furthermore, the participating $\mathrm{CHCs}$ are distributed widely across upstate New York, four boroughs of New York City, Northern New Jersey, and serve lowincome, African American patient populations. 
Utilization of EHRs among the participating sites at the time of recruitment and intervention was relatively low, and approximately one-half of the $\mathrm{CHCs}$ participating in the trial were involved in the HRSA Health Disparities Collaborative, an initiative that focuses on improving access to quality healthcare and improved health outcomes among medically underserved in order to reduce or eliminate health disparities [53].

Several strengths of the CAATCH trial deserve consideration. The first is that $\mathrm{CAATCH}$ is an evidencebased multi-level intervention in a very large exclusively African American practice-based sample, in contrast to previous efficacy and recent effectiveness trials in which the rate of African American participation has been more modest $[6,7,11,34,48,54]$. Second, CAATCH inclusion criteria allowed for the participation of patients with uncontrolled BP and those taking multiple medications, while the exclusion criteria of previous efficacy studies $[6,7,11]$ were more conservative by comparison. Third, CAATCH joins a small number of effectiveness trials (implemented in the VA [49] or community based primary care clinics [34]) in efforts to deliver efficacious treatments in real-world primary care settings. $\mathrm{CAATCH}$ is one of few studies to address barriers to $\mathrm{BP}$ control in this patient population by evaluating the effectiveness of a practice-based intervention targeted at patients (home BP monitoring, lifestyle intervention plus patient education) and physicians (chart audit and feedback plus physician education). Thus, findings from this trial will extend our understanding of applicability and impact of a multi-level intervention in a population whose hypertension may be particularly difficult to control.

We should note the following limitations of the CAATCH trial. First, similar to other large scale RCTs in African Americans, majority of CAATCH participants were women, making the results less generalizable to African American men. Second, there were imbalances in several important baseline patient characteristics between the IC and UC study sites, which raises potential threats to internal validity of the study findings. The cluster randomized design of the study sought to minimize baseline differences between both groups via matching of $\mathrm{CHCs}$ based on practice size. The reason for the observed baseline differences is not clear. One potential explanation for this imbalance may be the small number of sites that were randomized rather than the number of participants. Although the intraclass correlation coefficient (ICC) between the sites on these variables was quite small $[24,55]$, the additional matching of sites by size may have required larger number of sites than the proposed 30 sites. Alternative approaches to mitigate this problem maybe the use of a factorial design with randomization at the level of the providers on characteristics, such as number of years practicing in a community-based setting, size of caseload, and number of hypertensive patients in current caseload. This is the approach adopted by Corsino et al. [56], which often requires matching on lesser number of variables than sites and manageable number of providers and patients needed for the study. Other approaches of randomizing at the patient level with matching may also mitigate this problem, but such an approach is limited by the potential for contamination that is often a problematic in practice-based trials using such design, and the loss of the ability to examine the contribution of matching variables to changes in study outcomes.

In summary, the demographic and clinical composition of the CAATCH trial participants represents an important contribution to the literature on interventions targeted at poor BP control in a high-risk population. Namely, the trial includes implementation of a multilevel, evidence-based, intervention in a real-world setting among participants who experience multiple demographic, clinical, psychosocial, and behavioral barriers to hypertension control. Findings from this trial have important implications for dissemination and implementation. First, successful conduct of this study will be an indication that complex multi-level intervention can be integrated into care of high-risk hypertensive African Americans who receive care in CHCs. Second, imbalance noted in the baseline data indicates that investigators considering cluster RCT design in this patient population should strongly consider enrolling a larger number of sites and possibly an alternative design with randomization at the provider level. Third, recruitment of this high-risk patient population was achieved with significant cooperation from the clinical and administrative staff at the participating CHCs. A major lesson learned in this regard is the underlying assumption that all $\mathrm{CHCs}$ do not operate in the same manner. While their payment structure may be similar, the staffing in these sites is quite varied in terms of the use of allied health providers and availability of health educators who can provide lifestyle counseling and patient education. Furthermore, the level of enthusiasm for pragmatic trials is quite different for each $\mathrm{CHC}$, with some having more research experience and others lacking experience. This factor affected recruitment rates, follow-up rates, and delivery of the intervention. Specifically, sites that were more research-friendly had the highest completion rates with easier delivery of the intervention. Future practicebased research should better characterize the research sites along these dimensions in order to facilitate implementation of such complex studies and to assess the interaction between aspects of study implementation and $\mathrm{CHC}$ trial characteristics. Fourth, implementation of the patient level component of the intervention, 
including lifestyle counseling, could be strengthened by a flexible delivery format. For example, we found that a combination of in-person intervention sessions coupled with telephone check-in or booster sessions to support patient up-take of new skills allowed us to improve treatment fidelity levels.

\section{Conclusions}

The CAATCH trial is the first of its kind to focus on the effectiveness of a multi-level intervention for BP control in a large, socio-demographically and clinically diverse sample of hypertensive African American patients receiving primary care in safety-net settings. Given characteristics of the CHCs and participants, $\mathrm{CAATCH}$ has the potential to extend our understanding of barriers and facilitators of BP control in a group that experiences significant hypertension-related morbidity and mortality.

\begin{abstract}
Acknowledgements
This study was supported by the National Heart, Lung, and Blood Institute (NHLBI) grant number R01 HL78566 (PI: Ogedegbe), National Institutes of Health (NIH), Bethesda, MD, USA. Dr. Fernandez was supported by an American Heart Association (AHA) Heritage Affiliate Clinically Applied Research Grant; the NIH Loan Repayment Program (LRP) in Health Disparities Research. Dr. Ogedegbe was supported by a grant from the National Center for Minority Health and Health Disparities (NCMHD, Program Project \# 2P60 MD000206), NIH, Bethesda, MD, USA. The contents of this paper are solely the responsibility of the authors and do not necessarily represent the official views of the NHLBI, NCMHD, NIH LRP, or AHA. The funding agencies did not play a role in the study design; collection, analysis, and interpretation of data; the preparation of the manuscript; the decision to submit the manuscript for publication. We wish to acknowledge the significant efforts of the participating CHCs, clinicians and other staff, NYU and CDN Research Assistants. We express our gratitude for the time and effort of all of the study participants, without whom this study would not have been possible. Participating CHCs included Bedford Stuyvesant Family Health Center Brooklyn, NY; Betances Health Unit, NY, NY; Brookdale Hospital - Linden Boulevard Practice, Brooklyn, NY; Brookdale Hospital - New Lots Practice, Brooklyn, NY; Brookdale Hospital - Urban Strategies Practice, Brooklyn, NY; Brownsville Multi-Service Family Health Center, Brooklyn, NY; Caribbean American Family Health Center, Brooklyn, NY; CitiCare Inc., NY, NY; Community Health Care Network - Caribbean House, Brooklyn, NY; Community Health Care Network - Helen B. Atkinson Center, NY, NY; Community Health Care Network - Betty Shabaaz CHC, Brooklyn NY; Flatbush Avenue Health Center of Brookdale Hospital, Brooklyn, NY; Greenburgh Health Center, Inc., White Plains, NY; Heritage Health Care Center, New York, NY; Hudson River Health Center, Peekskill, NY; Joseph P. Addabbo Health Center - Central Avenue, Far Rockaway, NY; Joseph P. Addabbo Health Center, Jamaica, NY; Manhattan Physicians Group, 95th Street, NY, NY; Manhattan Physicians Group, New York, NY; Manhattan Physicians Group, Washington Heights, New York, NY; Metropolitan Family Health Network, Jersey City, NJ; Morris Heights Health Center, Bronx, NY; Mount Vernon Health Center, Mount Vernon, NY; Newark Community Health Center at Ludlow, Newark, NJ; Newark Community Health Center, Newark, NJ; Ossining Open Door Health Center, Ossining, NY; Plainfield Neighborhood Health Center, Plainfield, NJ; Soundview Health Center Delaney Sisters, Bronx, NY; Soundview Health Center, Bronx, NY; Urban Health Plan, Bronx, NY.
\end{abstract}

\section{Author details}

${ }^{1}$ Center for Healthful Behavior Change, Division of General Internal Medicine, Department of Medicine, New York University School of Medicine, 550 First Avenue, New York, NY, USA. ${ }^{2}$ Clinical Directors Network (CDN), 5 West $37^{\text {th }}$
Street, New York, NY, USA. ${ }^{3}$ Department of Epidemiology and Population Health, Albert Einstein College of Medicine of Yeshiva University, 1300 Morris Park Avenue, Bronx, NY, USA.

\section{Authors' contributions}

SF participated in the design, coordination and analysis of the study. AC, MDG, and CK participated in the coordination of the study. GO and JNT conceived of the study and participated in the design, coordination, and analysis of the study. All authors contributed to the preparation of the manuscript, and read and approved the final manuscript.

\section{Competing interests}

The authors declare that they have no competing interests.

Received: 1 September 2010 Accepted: 1 September 2011

Published: 1 September 2011

\section{References}

1. Fields LE, Burt VL, Cutler JA, Hughes J, Roccella EJ, Sorlie P: The burden of adult hypertension in the United States 1999 to 2000: a rising tide. Hypertension 2004, 44:398-404.

2. Cutler JA, Sorlie PD, Wolz M, Wolz M, Thom T, Fields LE, Roccella EJ: Trends in hypertension prevalence, awareness, treatment, and control rates in United States adults between 1988-1994 and 1999-2004. Hypertension 2008, 52(5):818-827.

3. Giles T, Aranda JM Jr, Suh DC, Choi IS, Preblick R, Rocha R, Frech-Tamas F: Ethnic/racial variations in blood pressure awareness, treatment, and control. Journal of Clinical Hypertension 2007, 9(5):345-354.

4. Gu Q, Burt VL, Paulose-Ram R, Yoon S, Gillum RF: High blood pressure and cardiovascular disease mortality risk among U.S. adults: the third National Health and Nutrition Examination Survey mortality follow-up study.[erratum appears in Ann Epidemiol. 2008 Jun;18(6):515]. Annals of Epidemiology 2008, 18(4):302-309.

5. Chobanian AV, Bakris GL, Black HR, Cushman WC, Green LA, Izzo JL Jr, Jones DW, Materson BJ, Oparil S, Wright JT Jr, Roccella EJ: Seventh report of the Joint National Committee on Prevention, Detection, Evaluation, and Treatment of High Blood Pressure. Hypertension 2003, 42(6):1206-1252

6. Appel LJ, Champagne CM, Harsha DW, Cooper LS, Obarzanek E, Elmer PJ, Stevens VJ, Vollmer WM, Lin PH, Svetkey LP, Stedman SW, Young DR: Effects of comprehensive lifestyle modification on blood pressure control: main results of the PREMIER clinical trial. JAMA 2003, 289(16):2083-2093.

7. Appel L, Espeland MA, Easter L, Wilson AC, Folmar S, Lacy CR: Effects of reduced sodium intake on hypertension control in older individuals: results from the Trial of Nonpharmacologic Interventions in the Elderly (TONE). Arch Intern Med 2001, 161(5):685-693.

8. Boulware LE, Daumit GL, Frick KD, Minkovitz CS, Lawrence RS, Powe NR: An evidence-based review of patient-centered behavioral interventions for hypertension. Am J Prev Med 2001, 21(3):221-232.

9. Fahey T, Schroeder K, Ebrahim S: Interventions used to improve control of blood pressure in patients with hypertension. Cochrane Database Syst Rev 2006, , 2: CD005182.

10. Sacks FM, Svetkey LP, Vollmer WM, Appel LJ, Bray GA, Harsha D, Obarzanek E, Conlin PR, Miller ER, Simons-Morton DG, Karanja N, Lin PH: Effects on blood pressure of reduced dietary sodium and the Dietary Approaches to Stop Hypertension (DASH) diet. DASH-Sodium Collaborative Research Group. N Engl J Med 2001, 344(1):3-10.

11. Appel L, Moore TJ, Obarzanek E, Vollmer WM, Svetkey LP, Sacks FM, Bray GA, Vogt TM, Cutler JA, Windhauser MM, Lin PH, Karanja N: A clinical trial of the effects of dietary patterns on blood pressure. DASH Collaborative Research Group. N Engl J Med 1997, 336(16):1117-1124.

12. Ogedegbe G, Tobin JN, Fernandez S, Gerin W, Diaz-Gloster M, Cassells A, Khalida C, Pickering T, Schoenthaler A, Ravenell J: Counseling African Americans to Control Hypertension (CAATCH) trial: A multi-level intervention to improve blood pressure control in hypertensive Blacks. Circulation: Cardiovascular Quality and Outcomes 2009, , 2: 249-256.

13. Altman DG, Schulz KF, Moher D, Egger M, Davidoff F, Elbourne D, Gøtzsche PC, Lang T: The revised CONSORT statement for reporting randomized trials: explanation and elaboration. Ann Intern Med 2001, 134(8):663-694. 
14. Perloff D, Grim C, Flack J, Frohlich ED, Hill M, McDonald M, Morgenstern BZ: Human blood pressure determination by sphygmomanometry. Circulation 1993, 88(5 Pt 1):2460-2470.

15. Morisky DE, Green LW, Levine DM: Concurrent and predictive validity of a self-reported measure of medication adherence. Med Care 1986, 24(1):67-74

16. Ogedegbe G, Mancuso CA, Allegrante JP, Charlson ME: Development and evaluation of a medication adherence self-efficacy scale in hypertensive African-American patients. J Clin Epidemiol 2003, 56(6):520-529.

17. Davis TC, Crouch MA, Long SW, Jackson RH, Bates P, George RB, Bairnsfather LE: Rapid assessment of literacy levels of adult primary care patients. Fam Med 1991, 23(6):433-435.

18. Gans KM, Ross E, Barner CW, Wylie-Rosett J, McMurray J, Eaton C: REAP and WAVE: New Tools to Rapidly Assess/Discuss Nutrition with Patients. Journal of Nutrition 2003, 133:556S-562S

19. Paffenbarger RS, Blair SN, Lee IM, Hyde RT: Measurement of physical activity to assess health effects in free-living populations. Med Sci Sports Exerc 1993, 25(1):60-70

20. Johns MW: A new method for measuring daytime sleepiness: the Epworth sleepiness scale. Sleep 1991, 14(6):540-545.

21. Kroenke K, Spitzer RL, Williams JB: The PHQ-9: validity of a brief depression severity measure. J Gen Intern Med 2001, 16(9):606-613.

22. Ware JE, Kosinski M, Keller SD: A 12-Item Short-Form Health Survey: Construction of scales and preliminary tests of reliability and validity. Medical Care 1996, 34(3):220-233.

23. Wagner EH, Austin BT, Davis C, Hindmarsh M, Schaefer J, Bonomi A: Improving chronic illness care: translating evidence into action. Health Aff (Millwood) 2001, 20(6):64-78.

24. Gerin W, Tobin JN, Schwartz JE, Chaplin W, Rieckmann N, Davidson KW, Goyal TM, Jhalani J, Cassells A, Feliz K, Khalida C, Diaz-Gloster M, Ogedegbe G: The medication Adherence and Blood Pressure Control $(A B C)$ trial: a multi-site randomized controlled trial in a hypertensive, multi-cultural, economically disadvantaged population. Contemporany Clinical Trials 2007, 28(4):459-471.

25. SAS System for Mixed Models [computer program] Version Cary, NC: SAS Institute Inc.

26. SAS Technical Report P-229, SAS/STAT Software: Changes and Enhancements [computer program] Version Cary, NC: SAS Institute Inc; 1992.

27. Hedeker D, Gibbons RD: A random-effects ordinal regression model for multilevel analysis. Biometrics 1994, 50(4):933-944.

28. Hedeker D, Gibbons RD: MIXOR: a computer program for mixed-effects ordinal regression analysis. Comput Methods Programs Biomed 1996, 49(2):157-176

29. Johns M, Hocking B: Daytime sleepiness and sleep habits of Australian workers. Sleep 1997, 20(10):844-849.

30. Victor RG, Haley RW, Willett DL, Peshock RM, Vaeth PC, Leonard D, Basit M, Cooper RS, lannacchione VG, Visscher WA, Staab JM, Hobbs HH: The Dallas Heart Study: a population-based probability sample for the multidisciplinary study of ethnic differences in cardiovascular health. American Journal of Cardiology 2004, 93(12):1473-1480.

31. Albert MA, Ravenell J, Glynn RJ, Khera A, Halevy N, de Lemos JA: Cardiovascular risk indicators and perceived race/ethnic discrimination in the Dallas Heart Study. American Heart Journal 2008, 156(6):1103-1109.

32. Taylor HA Jr, Wilson JG, Jones DW, Sarpong DF, Srinivasan A, Garrison R. Nelson C, Wyatt SB: Toward resolution of cardiovascular health disparities in African Americans: design and methods of the Jackson Heart Study. Ethnicity \& Disease 2005, 15(4 Suppl 6):S6-4-17.

33. Wyatt SB, Akylbekova EL, Wofford MR, Coady SA, Walker ER, Andrew ME, Keahey WJ, Taylor HA, Jones DW: Prevalence, awareness, treatment, and control of hypertension in the Jackson Heart Study. Hypertension 2008, 51(3):650-656

34. Svetkey LP, Pollak KI, Yancy WS Jr, Dolor RJ, Batch BC, Samsa G, Matchar DB, $\mathrm{Lin} \mathrm{PH}$ : Hypertension improvement project: randomized trial of quality improvement for physicians and lifestyle modification for patients. Hypertension 2009, 54(6):1226-1233.

35. Flegal KM, Carroll MD, Ogden CL, Curtin LR: Prevalence and trends in obesity among US adults, 1999-2008. JAMA 303(3):235-241, Jan 20;

36. Ogden $\mathrm{CL}$, Carroll MD, Curtin LR, McDowell MA, Tabak CJ, Flegal KM: Prevalence of overweight and obesity in the United States, 1999-2004. JAMA 2006, 295(13):1549-1555.
37. Haynes RB, Ackloo E, Sahota N, McDonald HP, Yao X: Interventions for enhancing medication adherence. Cochrane Database Syst Rev 2008, , 2: CD000011.

38. Ogedegbe G, Chaplin W, Schoenthaler A, Statman D, Berger D, Richardson T, Phillips E, Spencer J, Allegrante JP: A practice-based trial of motivational interviewing and adherence in hypertensive African Americans. Am J Hypertens 2008, 21(10):1137-1143.

39. Osterberg L, Blaschke T, Osterberg L, Blaschke T: Adherence to medication. New England Journal of Medicine 2005, 353(5):487-497.

40. Wong ND, Lopez VA, L'Italien G, Chen R, Kline SE, Franklin SS: Inadequate control of hypertension in US adults with cardiovascular disease comorbidities in 2003-2004. Archives of Internal Medicine 2007, 167(22):2431-2436.

41. McDowell MA, Hughes JP, Borrud LG, McDowell MA, Hughes JP, Borrud LG: Health characteristics of U.S. adults by body mass index category: results from NHANES 1999-2002. Public Health Reports 2006, 121(1):67-73, Reprint in MMWR Morb Mortal Wkly Rep. 2006 Jun 16;55(23):656; PMID: 16789325

42. Qureshi Al, Giles WH, Croft JB, Bliwise DL: Habitual sleep patterns and risk for stroke and coronary heart disease: a 10-year follow-up from NHANES I. Neurology 1997, 48(4):904-911.

43. Kapur VK, Resnick HE, Gottlieb DJ: Sleep disordered breathing and hypertension: does self-reported sleepiness modify the association? Sleep 2008, 31(8):1127-1132

44. Young T, Peppard PE, Gottlieb DJ, Young T, Peppard PE, Gottlieb DJ: Epidemiology of obstructive sleep apnea: a population health perspective. American Journal of Respiratory \& Critical Care Medicine 2002, 165(9):1217-1239.

45. Young T, Skatrud J, Peppard PE, Young T, Skatrud J, Peppard PE: Risk factors for obstructive sleep apnea in adults. JAMA 2004, 291(16):2013-2016

46. Muntner P, Krousel-Wood M, Hyre AD, Stanley E, Cushman WC, Cutler JA, Piller LB, Goforth GA, Whelton PK: Antihypertensive prescriptions for newly treated patients before and after the main antihypertensive and lipid-lowering treatment to prevent heart attack trial results and seventh report of the joint national committee on prevention, detection, evaluation, and treatment of high blood pressure guidelines. Hypertension 2009, 53(4):617-623.

47. Svetkey LP, Harsha DW, Vollmer WM, Stevens VJ, Obarzanek E, Elmer PJ, Lin $\mathrm{PH}$, Champagne C, Simons-Morton DG, Aickin M, Proschan MA, Appel $\sqcup$ : Premier: a clinical trial of comprehensive lifestyle modification for blood pressure control: rationale, design and baseline characteristics. Ann Epidemiol 2003, 13(6):462-471.

48. Dolor RJ, Yancy WS Jr, Owen WF, Matchar DB, Samsa GP, Pollak KI, Lin PH Ard JD, Prempeh M, McGuire HL, Batch BC, Fan W, Svetkey LP: Hypertension Improvement Project (HIP): study protocol and implementation challenges. Trials 2009, 10:13.

49. Bosworth HB, Olsen MK, Dudley T, Orr M, Goldstein MK, Datta SK, McCant F, Gentry P, Simel DL, Oddone EZ: Patient education and provider decision support to control blood pressure in primary care: a cluster randomized trial. American Heart Journal 2009, 157(3):450-456.

50. Roumie CL, Elasy TA, Greevy R, Griffin MR, Liu X, Stone WJ, Wallston KA, Dittus RS, Alvarez V, Cobb J, Speroff T: Improving blood pressure control through provider education, provider alerts, and patient education: a cluster randomized trial. Annals of Internal Medicine 2006, 145(3):165-175.

51. Bosworth HB, Olsen MK, Grubber JM, Neary AM, Orr MM, Powers BJ, Adams MB, Svetkey LP, Reed SD, Li Y, Dolor RJ, Oddone EZ: Two Selfmanagement Interventions to Improve Hypertension Control. Annals of Internal Medicine 2009

52. Ford JG, Howerton MW, Lai GY, Gary TL, Bolen S, Gibbons MC, Tilburt J, Baffi C, Tanpitukpongse TP, Wilson RF, Powe NR, Bass EB: Barriers to recruiting underrepresented populations to cancer clinical trials: A systematic review. Cancer 2008, 112(2):228-242.

53. Hicks LS, O'Malley AJ, Lieu TA, Keegan T, McNeil BJ, Guadagnoli E, Landon BE: Impact of health disparities collaboratives on racial/ethnic and insurance disparities in US community health centers. Archives of Internal Medicine 2010, 170(3):279-286.

54. Bosworth HB, Olsen MK, Dudley T, Orr M, Goldstein MK, Datta SK, McCant F, Gentry P, Simel DL, Oddone EZ: Patient education and provider decision support to control blood pressure in primary care: A cluster randomized trial. American Heart Journal 2009, 157(3):450-456. 
55. Schoenthaler A, Chaplin WF, Allegrante JP, Fernandez S, Diaz-Gloster M, Tobin JN, Ogedegbe G: Provider communication effects medication adherence in hypertensive African Americans. Patient education and counseling 2009, 75(2):185-191.

56. Corsino L, Yancy WS, Samsa GP, Dolor RJ, Pollak KI, Lin PH, Svetkey LP: Physician Characteristics as Predictors of Blood Pressure Control in Patients Enrolled in the Hypertension Improvement Project (HIP). J Clin Hypertens (Greenwich) 2011, 13(2):106-111.

doi:10.1186/1748-5908-6-100

Cite this article as: Fernandez et al:: The counseling african americans to control hypertension (caatch) trial: baseline demographic, clinical,

psychosocial, and behavioral characteristics. Implementation Science 2011 6:100

\section{Submit your next manuscript to BioMed Central} and take full advantage of:

- Convenient online submission

- Thorough peer review

- No space constraints or color figure charges

- Immediate publication on acceptance

- Inclusion in PubMed, CAS, Scopus and Google Scholar

- Research which is freely available for redistribution

Submit your manuscript at www.biomedcentral.com/submit 